\title{
Suspected Central Anticholinergic Syndrome Related to Cycloplegic Eye Drop in a Premature Baby
}

\author{
Nurdan Bedirli ${ }^{1}$, Fatma Akgün ${ }^{1}$, Ahmet Hondur², Berrin Işık ${ }^{1}$ \\ ${ }^{1}$ Department of Anesthesiology and Reanimation, Faculty of Medicine, Gazi University, Ankara, Turkey \\ ${ }^{2}$ Department of Ophthalmology, Faculty of Medicine, Gazi University, Ankara, Turkey
}

\begin{abstract}
The therapeutic approach for the central anticholinergic syndrome after application of cycloplegic eye drops in a premature infant patient who was scheduled for laser photocoagulation under general anesthesia is reviewed in the light of the relevant literature.
\end{abstract}

Key Words: Central anticholinergic syndrome, cyclopentolate, eye drops

Received: 13.02.2012 Accepted: 05.07.2012

\section{Introduction}

Cholinergic activity is associated with sleep-wakefulness, memory, awareness, orientation and analgesia in the central nervous system (CNS) and myosis and maintenance of tear secretion in the eyes.

Synthetic belladonna alcoloids are used to obtain mydriasis and cycloplegia in eye surgery. When cycloplegic eye drops are applied at over the recommended doses or anticholinergics are administered systemically, CNS effects can be seen $(1,2)$.

The central anticholinergic syndrome (CAS) which was first described in 1966 by Longo, comprises of the findings of restlessness, agitation, hallucination, disorientation convulsions, stupor or respiratory failure, and coma (3).

CAS is frequently seen after atropine and scopolamine implementation. However, opiates, benzodiazepines phenothiazines, butyrophenon, antihistamines, ketamine, cimetidine, etomidate, propofol, nitrous oxide and volatile anesthetics have also been reported be causes of CAS. Frequencies of CAS between 1-11.2\% have been reported after general anesthesia. CAS is well-defined in elderly adults but it has only been reported rarely in children (4-9), and only a single case in infants (5).

In this case report we aimed to present an infant who developed CAS after an over dose of cycloplegic drops, and to discuss this in the light of the literature.

\section{Case Report}

A female patient with the diagnosis of retinopathy of prematurity (ROP) was scheduled for bilateral laser photocoagu- lation under general anesthesia. She was 3 months old (corrected age) and weighed $4650 \mathrm{~g}$.

The baby was diagnosesd as broncho-pulmonary dysplasia, hypo-thyroidism, ovarian hyper-stimulation, gastroesophageal reflux and was hospitalsied in the newborn department. Vital signs were stable, and routine blood tests were within the normal clinical range at the preoperative visit.

After a 4 hour fasting period, she was brought to the operating table in the incubator, but she was agitated and had seizures and restlessness. At physical examination her pupils were mydriatic, her skin was dry, hot and reddish. Breath sounds were symmetrically rough. Extra rales or rhonchii were not heard. Electrocardiography (ECG), heart rate [(HR): 225/ regular)], oxygen saturation $\left[\left(\mathrm{SpO}_{2}\right): 89 \%\right]$ were monitored. Rectal body temperature $\left(40.2^{\circ} \mathrm{C}\right)$ was measured. The cycloplegic agent used and its doses in the unpremedicated baby were questioned. Although administration of 3 drops of $0.5 \%$ cycloplegic eye drops ( $1 \%$ Sikloplejin $\left.{ }^{\circledR}\right)$ within a 30 minute interval was ordered, $0.5 \%$ cyclopentolate hydrochloride were accidentally dropped 5 times.

Physostigmine was not given to the patient who was diagnosed with central anticholinergic syndrome because the drug was not available in Turkey. The operation was postponed and the baby monitored under close observation. Rectal temperature was increased to $40.5^{\circ} \mathrm{C} .35 \mathrm{mg}$ Paracetamol (Perfalgan® $10 \mathrm{mg} / 100 \mathrm{~mL}$, Bristol Myers Squibb) was given intravenously. A cold pack was applied externally. Approximately 4 hour later, all symptoms had disappeared, and body temperature was decreased to $36.8^{\circ} \mathrm{C}$. The operation was planned one day later.

Cycloplegic drops (0.5\%) were instilled into her eyes three times during the operation morning. Isodex $(29 \mathrm{~mL} / \mathrm{h} 1 / 3$

This case report was presented as a poster at the $3^{\text {rd }}$ World Congress of Ophthalmic Anaesthesia, $24^{\text {th }}$ of May 2012

Address for Correspondence: Dr. Nurdan Bedirli, Department of Anesthesiology and Reanimation, Faculty of Medicine, Gazi University, Ankara, Turkey Phone: +90312 2026254 E-mail: nurbedirli@gazi.edu.tr 
İodeks ${ }^{\circledR}$ ) infusion was continued intravenously. Anesthesia induction was achieved with $8 \%$ sevoflurane inhalation, and maintained by $2 \%$ sevoflurane in a $40 / 60 \mathrm{O}_{2}$ /air mixture after orotracheal intubation. $\mathrm{EtCO}_{2}$ pressure was controlled within a $30-32 \mathrm{mmHg}$ ranges. At the end of the operation, the endotracheal tube was removed. The patient's abdomen was then ausculated in each quadrant. Gastric distention was resolved by nasogastric tube placement. The patient was closely observed in an incubator in the recovery room during a one hour period. Heart rate (140 beat/min, $\mathrm{SpO}_{2} 98 \%$ ) was recorded. The patient was transferred to the ward and discharged after a one night hospitalization period.

\section{Discussion}

Cholinergic activity affects sleep-wakefulness, memory, awareness, orientation and analgesia. Acetylcholine (Ach) and Ach receptors are widely distributed in the brain to maintain cholinergic activity. Total or relative decrease in cholinergic activity in the CNS is defined as the CAS. Excitation or depression symptoms can be seen due to CNS effects of the Ach and are associated with the CAS findings. These include seizures, excitation, hallucinations, disorientation, hyperpyrexia, hyperalgesia, ataxia, mental deficiency, sedation and coma (2-10). In the presented case, restlessness, jerky limb movements, skin rash, dryness, fever, tachycardia were present.

Cyclopentolate $\mathrm{HCl}$ has been used to produce mydriasis in ophthalmology for a long time (1). Cyclopentolates like atropine have antimuscarinic effects, and have a tertiary amine structure. Cyclopentolate eye drops may mix with the systemic circulation via absorbtion from the eye mucosa and nasolacrimal duct $(1,6,7)$. Acute psychosis is one of the CAS signs and can be seen after topical anticholinergic application in low weight children. Toxicity increases in relation to the drug dose/body weight ratio. Symptoms of the CAS might appear 20-30 minutes after eye drop instillation, and continue for 4-8 hours, occasionally recovering uneventfully $(6,7)$. In this case report, clinical signs appeared 30 minutes after the drop instillation to the eye, and symptoms disappeared in 5 hours. This effect may be explained by the absorption of cyclopentolate by brain tissue via the capillary system, deep cerebral veins and sinus cavernous.

Clinical signs of the CAS might be similar to those of metabolic endocrine disorders such as hyperthermia, hypothermia, acid-base disturbances, hypothyroidism, hyper-hypoglycemia, hyperpyrexia or cerebral ischemia, intracranial mass cerebral edema, trauma, acute psychosis, and epilepsy. For this reason, diagnoses should be checked before starting the treatment of CAS (8). In this case report, bronchopulmonary infection, sepsis and hypothyroidism were kept in mind for the differential diagnosis. However patients with a medical history and laboratory signs are not compatible with the disease. Furthermore, overuse of cycloplegic eye drops was revealed, and CAS treatment was planned. Symptomatic treatment was achieved by external cooling and intravenous paracetamol infusion.

If the patient had the diagnosis of CAS, physostigmine, neostigmine or edrophonium might be given for treatment. As their structures are quarternary amines, they cannot cross the blood brain barrier, and neostigmine, physostigmine, and edrophonium are used to treat peripheral effects of atropine, scopolamine and other anticholinergic drug overdoses. Physostigmine, because it is a tertiary amine (and thus does not bind to hydrogen) it can cross the blood-brain barrier, and is used to treat the central effects of anticholinergic drug overdoses. Physostigmine increases Ach as a competitive inhibitor of the Ach esterase. Its effects emerge in five minutes. Recommended doses of physostigmine are $0.02 \mathrm{mg} / \mathrm{kg}$ in a 1-2 minute period and the dose is repeated every 5 minutes until completion of the total $2 \mathrm{mg}$ dose in children and young patients. If the desired effects are not obtained, this drug regime might be repeated 20 minutes after the last dose. The primary dose is $2 \mathrm{mg}$ and the second dose 1 to $2 \mathrm{mg}$ in young children. In insufficiency of the drug, this dose regime might be repeated 20 minutes later (9). In this case report we did not use physostigmine because it is not available in Turkey.

Agitation and restlessness might be treated with sedative agents such as midazolam. However, midazolam can have harmful effects in patients with respiratory failure. In our case, we did not use midazolam.

\section{Conclusion}

Due to cycloplegic eye drop CAS may occur in babies. Doses of the cycloplegic in eye drop must be determined keeping in mind the systemic effects.

\section{Conflict of Interest}

No conflict of interest was declared by the authors.

\section{References}

1. Gray C. Systemic toxicity with topical ophthalmic medications in children. Paediatric and Perinatal Drug Therapy 2006;7:23-9. [CrossRef]

2. Rizzi RR, Ho J. Post resuscitation central anticholinergic syndrome. Resuscitation 2004;61:101-2. [CrossRef]

3. Longo VG. Behavioral and electroencephalographic effects of atropine and related compounds. Pharmacol Rev 1966;18:965-96.

4. Schultz U, Idelberger R, Rossaint R, Buhre W. Central anticholinergic syndrome in a child undergoing circumcision. Acta Anaesthesiol Scand 2002;46:224-6. [CrossRef]

5. Kulka PJ, Toker H, Heim J, Joist A, Jakschik J. Suspected central anticholinergic syndrome in a 6-week-old infant. Anesth Analg 2004;99:1376-8. [CrossRef]

6. Baysal Z, Cengiz M, Oğuz H, Ganidağlı S. Central Anticholinergic Syndrome Induced by Cyclopentolate Eye Drops in A 4 Year Old Child. The Internet Journal of Emergency and Intensive Care Medicine 2006:9(1).

7. Bhatia SS, Vidyashankar C, Sharma RK, Dubey AK. Systemic toxicity with cyclopentolate eye drops. Indian Pediatr 2000;37:329-31.

8. Amerikan Psikiyatri Birliği. Mental Bozuklukların Tanısal ve Sayımsal El Kitabı. Yeniden gözden geçirilmiş 4. baskı (DSMIV-TR), Washington D.C., Amerikan Psikiyatri Birliği, E Köroğlu (2000'den Çev.), Ankara, Hekimler Yayın Birliği, 2001:74-75.

9. Orhan O, Senoğlu N, Bağcıoğlu E, Demirkan H. Central anticholinergic syndrome associated with atropine: case report. Anatol J Clin Investig 2008:2:45-6.

10. Rumack $\mathrm{BH}$. Anticholinergic poisoning: treatment with physostigmine. Pediatrics 1973;52:449-51. 